\title{
POLÍTICAS TERRITORIAIS E DESIGUALDADES NO MEIO RURAL BRASILEIRO
}

\section{TERRITORIAL POLICIES AND INEQUALITIES IN THE RURAL BRAZILIAN}

\author{
Armando Fornazier \\ Universidade Estadual de Campinas - Campinas - SP - Brasil \\ Walter Belik \\ Universidade Estadual de Campinas - Campinas - SP - Brasil
}

\begin{abstract}
Resumo: As desigualdades entre as regiões fazem com que ações de intervenção possam ser implementadas de forma diferenciada. No Brasil, o Grupo de Trabalho para o Desenvolvimento do Nordeste - GTDN é um marco histórico de um projeto para diminuir as desigualdades regionais, mas, com o tempo, a perda de poder do Estado pelas crises ocasionadas pelas altas dívidas e o ideário neoliberal fizeram com que as políticas regionais fossem deixadas de lado. Porém, com a manutenção e agravamento de muitos problemas quanto à desigualdade regional, viu-se a necessidade de ações e, para isso, criou-se a Política Nacional de Desenvolvimento Regional - PNDR com o objetivo de diminuir as desigualdades regionais e programas territoriais como o Territórios da Cidadania para as regiões rurais e com baixa dinâmica econômica. $O$ objetivo desse trabalho é verificar como as políticas públicas podem atuar na diminuição das disparidades entre as regiões e grupos sociais, dando ênfase à política de desenvolvimento territorial denominada Territórios da Cidadania. Utiliza-se, para atingir os objetivos, a pesquisa bibliográfica e documental. A articulação entre os atores sociais e as diferentes esferas do governo é o principal enfoque das políticas territoriais. Cada vez mais, o território passa a ser um mecanismo para delimitar ações de políticas públicas, ou seja, o território não é compreendido apenas como um espaço geográfico, mas também como um espaço de articulação. Além disso, busca-se uma interação do rural com o urbano, tanto nos incentivos às atividades produtivas quanto na oferta de benefícios sociais, tanto constitucionais como serviços de infraestrutura. A participação, cada vez mais, faz parte do discurso, porém, há a necessidade de uma articulação do local com o nacional para um projeto de desenvolvimento com o objetivo de diminuir as desigualdades regionais.
\end{abstract}

Palavras-chaves: Desenvolvimento Rural. Políticas Públicas. Organização Social.

Abstract: Inequalities between regions make intervention actions be implemented differently. The Working Group for the Development of the Brazilian Northeast (GTDN) was a milestone of a project to reduce regional disparities. Nevertheless, the loss of 
state power by crises occasioned by the high debt and the neoliberal ideals have changed the character of the intervention in regional planning. Considering the aggravation of many problems concerning the regional inequality, the military created the National Policy for Regional Development (PNDR) with the aim of reducing regional inequalities and the territorial programs as Territories of Citizenship for rural and low economic dynamics. This article intends to assess how public policies can play in order to reduce disparities between regions and social groups, with emphasis on territorial development program called Territories of Citizenship. The link between social actors and the different spheres of government is the main focus of territorial programs and increasingly the territory becomes a mechanism to define public policy actions, i.e., the territory is not understood only as a geographical space but also as a space of articulation. In addition, this policy seeks to interact the rural and urban, both in the incentives for productive activities as the provision of social benefits, and also constitutional and infrastructure services. The participation is increasingly the part of the speech, however, there is a need for a joint action gathering local and national development projects aiming to reduce regional disparities.

Keywords rural development, public policy, social organization

\section{INTRODUÇÃO}

O processo de desenvolvimento econômico capitalista tem como característica gerar desigualdades entre indivíduos e regiões. Ao mesmo tempo em que muitas regiões avançam em várias atividades econômicas e melhorias das condições sociais, outras sofrem com a estagnação e a decadência. Com isso, aprofundam-se as desigualdades entre as regiões.

Em cada região, o componente histórico tem grande importância para se entender a situação atual, seja o componente de evolução econômica, como as atividades que predominaram, bem como os componentes sociológicos, por exemplo, o tipo de organização social predominante. Outros fatores que podem contribuir para os desequilíbrios regionais são o ambiental, que pode causar grandes problemas econômicos, por exemplo, os efeitos das secas que causam perdas em diversas regiões do país, especialmente no Nordeste brasileiro, bem como o componente político nas disputas entre regiões por meio de guerra fiscal.

Os problemas locais ou regionais não se mantêm isolados, ou seja, extrapolam esses níveis. Problemas como a baixa oferta nas oportunidades de trabalho em uma região ocasionam migrações para outras regiões, caso bem característico no Brasil com suas grandes 
migrações do campo para as cidades, promovendo um grande inchaço e uma série de problemas sociais urbanos, como a pobreza e os altos índices de desemprego.

Novos modos de vida também vão sendo difundidos de forma que se torna necessário seguir determinados parâmetros de crescimento. As pessoas passam a exigir acesso a determinados serviços, como luz, telefone, internet, entre outros. Além disso, parte dos serviços passa a ser considerada essencial e até mesmo constitucional, ou seja, cabe ao Estado oferecer serviços de infraestrutura, como água tratada e esgoto, bem como acesso aos serviços de saúde e educação. Os próprios índices que avaliam as disparidades entre as regiões ou grupos sociais fazem com que as ações de políticas públicas tenham que trabalhar na melhoria dos indicadores, pois, esse é o único objetivo para se obter melhorias.

Mesmo com o Estado saindo de muitas áreas em alguns períodos como na década de 1990 com as medidas neoliberais implementadas no Brasil, o setor privado não atendeu a muitas regiões ou grupos de indivíduos, como os que fornecem um menor retorno financeiro. Mesmo em alguns serviços que foram privatizados, como a telefonia, coube ao Estado oferecer incentivos em várias regiões que não eram consideradas atrativas para as empresas privadas.

As disparidades de acesso aos serviços ocorrem entre as regiões do país, mas, dentro de uma mesma região, também ocorrem entre grupos de pessoas, como a diferença de acesso a determinado serviço entre o morador da favela e o do bairro nobre, bem como entre o rural e o urbano. Nesse aspecto, principalmente no rural, seja para o morador do campo ou, até mesmo, para o residente na pequena cidade, problemas como a escala para a oferta de determinado bem público, como a água tratada, ou a pouca atratividade de uma empresa privada e mesmo de economia mista de oferecer serviços a essas áreas pouco atrativas, fazem com que fiquem marginalizadas. Isso requer, cada vez mais, um plano de ação por parte do Estado em busca de agir nessas áreas pouco atrativas ao capital com o objetivo de diminuir as disparidades regionais e/ou sociais.

Ao longo de muitos anos, ações foram executadas tentando diminuir as disparidades regionais, porém, as disparidades ocorrem além das regiões, elas também acontecem entre grupos de indivíduos. 
Dessa forma, muitas vezes, as ações passam a ser executadas por áreas menores, que possuem certas características em comum e que se distinguem de outras, por exemplo, os territórios.

Para diminuir as disparidades entre as regiões predominantemente rurais com baixa dinâmica econômica, e outras regiões que oferecem melhores condições de vida, surge a proposta do governo federal, em 2007, do Programa Territórios da Cidadania. Além de oferecer ao cidadão serviços constitucionais e de infraestrutura, o programa também busca reduzir as desigualdades incentivando inserções produtivas nessas regiões, como o apoio a determinadas atividades geradoras de emprego e renda.

Mesmo o rural, que por muito tempo foi visto como sinônimo de atraso, cada vez mais reivindica melhorias e modos de vida mais modernos. Dessa forma, requer que o Estado também tenha que oferecer esses serviços a esse grupo social.

O objetivo deste trabalho é verificar como as políticas públicas podem atuar na diminuição das disparidades entre as regiões e grupos sociais, dando ênfase à política de desenvolvimento territorial denominada Territórios da Cidadania. Porém, para isso, faz uma contextualização de políticas de desenvolvimento mais focadas no nível regional e, a partir daí, as ações mais específicas em determinado grupo social mais específico.

Para atender o objetivo do presente trabalho, a metodologia utilizada é a pesquisa bibliográfica e documental. Quanto à pesquisa bibliográfica, cabe verificar em livros, artigos, anais de eventos, etc. o que já foi publicado sobre o assunto e sistematizar quanto à temática sugerida. Segundo Gil (1991), a pesquisa bibliográfica tem a função de resgatar o que já foi publicado sobre determinado tema. Por meio da pesquisa documental, busca-se consultar o que há no debate do tema em outros meios de divulgação fora do meio acadêmico. Exemplos de documentos consultados para a presente pesquisa são os próprios relatórios de execução do programa, entrevistas transcritas em jornais e revistas não acadêmicas, consulta ao aparato jurídico e organizacional do programa, entre outros. Esta pesquisa tem grande importância em trazer questões recentes que ainda não estão no debate acadêmico, ou seja, não foram publicadas em outros meios ou, como afirma Minayo 
(2007), os materiais estudados na pesquisa documental ainda não receberam tratamento analítico.

Redes (St. Cruz Sul, Online), v. 20, n² 2, p. 47 - 68, maio/ago. 201551 


\section{DESIGUALDADES REGIONAIS}

As regiões brasileiras tiveram diferentes formas de desenvolvimento econômico de acordo com as características de ocupação do espaço, seja, pelo nível de organização das atividades e, até mesmo, pela incidência de determinados fatores como os ambientais. Cano (1991) destaca o tipo de atividade econômica instaurada no Estado de São Paulo que foi a cafeicultura e sua importância para a criação da atividade industrial, ou seja, a produção cafeeira utilizava-se de equipamentos para o beneficiamento de café, sacarias, etc. Outro fator destacado pelo autor é que essa atividade também foi ligando a outros setores de acumulação, como as infraestruturas em ferrovias, serviços bancários, bem como o tipo de relação social que predominava (assalariado) permitia a formação de uma indústria de bens de consumo, ou seja, nessas regiões, os trabalhadores podiam comprar alguns produtos, por exemplo, vestuários e alimentos, o que incentivava a criação de uma indústria desses bens, enquanto em outras regiões de produção cafeeira como nos Estados do Rio de Janeiro e Espírito Santo, o tipo de relação social como o regime escravista ou a parceria (meeiros) dificultavam a formação dessa indústria e um efeito de desenvolvimento regional.

Também, em outras atividades, os tipos de relações sociais predominantes não geraram os efeitos de linkages ou encadeamentos como descritos por Hirschmann (1985), o que levou a não superar o problema do subdesenvolvimento. Furtado (2006) mostra que, em atividades como no cultivo da cana-de-açúcar no Nordeste do Brasil, a renda disponível estava concentrada nas mãos de um restrito número de senhores de engenhos, uma vez que a população branca era rarefeita em relação aos indígenas e aos negros, que trabalhavam em regime de escravidão, tornando a economia pouco monetizada.

Assim, começam a surgir muitas disparidades no Brasil, pois, na medida em que uma região se desenvolve, mesmo que a outra permaneça no mesmo estágio de desenvolvimento, aumentam as disparidades entre as regiões. Cano (2007) destaca que as maiores taxas do crescimento industrial paulista ampliam uma maior concentração industrial em São Paulo. 
Para corrigir as disparidades, o governo federal lançou, em 1959, o projeto do GTDN que buscava, sobretudo, uma reestruturação econômica e social da região. O GTDN, que tinha como um dos seus principais articuladores Celso Furtado, forneceu um diagnóstico dos grandes problemas enfrentados pelo Nordeste, dentre esses, a grande disparidade do desenvolvimento da indústria no Nordeste com o Centro Sul, especialmente São Paulo, que possuía grande parte do Produto Interno Bruto - PIB industrial, o que causava uma deterioração dos termos de troca entre as regiões (característica do pensamento da Comissão Econômica para a América Latina e o Caribe - CEPAL na época). Como a economia do Nordeste crescia menos, as disparidades regionais tenderiam a aumentar. Outros problemas abordados pelo GTDN (1959) era o duplo fluxo de renda, de forma que o Nordeste recebia do governo federal os fluxos de renda, especialmente para obras assistenciais, porém, a renda gerada no Nordeste pelo setor privado gerava inversões em outras regiões, principalmente no Centro Sul.

Outros autores, por exemplo, Myrdal (1969), tratam dos problemas do subdesenvolvimento onde, introduzindo o princípio da causação circular e acumulativa, ou seja, o mesmo princípio adotado no estudo dos negros nos Estados Unidos é utilizado para avaliar as desigualdades econômicas regionais, mostrando as dificuldades das regiões subdesenvolvidas de se desenvolverem. Assim, o autor destaca a importância do papel do Estado em oferecer os serviços de infraestrutura, comunicações etc., que são medidas fundamentais contra a tendência à desigualdade regional.

Quanto à agropecuária, o GTDN (1959) relata que existia uma agricultura mais moderna e monetizada destinada à exportação (canade-açúcar e algodão), mas, principalmente no semiárido prevalecia o minifúndio que, com uma agricultura pouco monetizada, em períodos de perdas com fatores climáticos como as secas, sofria calamidades, pois o agricultor perdia o seu sustento e não possuía reservas monetárias para a sua subsistência, daí a grande dependência da ação do Estado em medidas assistenciais, seja pela doação de produtos ou pela criação de frentes de trabalho, ou seja, uma lógica de Estado keynesiano para promover demanda de forma a ativar ou impulsionar a 
economia. O documento abordava também outras questões, como os tributos, etc.

Além do diagnóstico, o documento fornecia a indicação de medidas que poderiam ser usadas para a diminuição das desigualdades regionais. Pelo diagnóstico, a única forma de incrementar o nível de renda da região seria desenvolver outras atividades, dentre essas, dá-se forte ênfase à industrialização. Para isso, justificava com fatores que permitiam a adoção das ações, como a presença de um mercado consumidor, oferta de energia elétrica, etc. Quanto à questão agrária, o documento previa uma reforma agrária na Zona da Mata, onde se cultivava cana-de-açúcar e a colonização dos hinterlands (vales úmidos do Maranhão) com parte da população do semiárido que vivia da agricultura de subsistência. Dentre as ações para a agropecuária, o que se buscava era romper com o modelo de agricultura pouco monetizada. Assim, começam a surgir as propostas de aplicação de determinadas técnicas na agricultura da região como a irrigação, ou seja, mesmo na cultura da cana-de-açúcar, podia-se liberar área, adotando mais tecnologia para se obter uma maior produtividade. Para Furtado (1972), a assertiva segundo a qual o avanço do progresso técnico nas atividades agrícolas eliminaria, necessariamente, o atraso e a miséria rural é o ponto central atacado pelo autor, pois o latifúndio constituía-se num meio de assegurar a uma minoria uma oferta elástica de mão de obra e impor à população certo padrão de distribuição de renda. Daí a importância de uma reforma agrária para modernizar o país, rompendo com a monocultura agroexportadora. A industrialização e a reforma agrária deveriam ser comandadas pelo Estado para alcançar o desenvolvimento.

Porém, antes mesmo da adoção por completo das ações do GTDN, surge o regime militar no Brasil em 1964. Parte das ações do programa se altera com o regime militar. Porém, o GTDN, com sua lógica e planejamento por parte do Estado, constitui-se um marco de um projeto brasileiro para corrigir as desigualdades entre as regiões. Mesmo que não tenha resolvido todos os problemas diagnosticados, algumas atividades como a formação de uma indústria na região foi com base em propostas do grupo de trabalho. Araujo e Santos (2009) relatam que o Nordeste saiu de seu entorpecimento secular e nos anos recentes vem crescendo a taxas médias superiores à nacional. Ao mesmo tempo em 
que o país consolidava a integração do mercado interno, o Nordeste se integrava a esta dinâmica, passando a acompanhar de perto a economia nacional.

A industrialização avançou na região com relevante papel da Superintendência de Desenvolvimento do Nordeste-SUDENE nesse movimento, e, como concentrou cerca de dois terços dos investimentos dos incentivos que administrava nas três principais áreas metropolitanas do Nordeste, foi ali que o setor industrial se ampliou mais e se diversificou. Muitas filiais de grandes grupos transnacionais e nacionais lá se instalaram, ampliando o peso da região no tecido produtivo nordestino, em especial no tecido metropolitano. O GTDN é o marco inicial para o que depois se denominou de SUDENE. Além disso, outros mecanismos como a criação de fundos constitucionais para determinadas regiões como o Nordeste também ofereceram estímulos para se investir nessas regiões.

No decorrer do tempo, outros fatores como a guerra fiscal entre alguns estados fez com que aumentassem as disparidades mesmo dentro das regiões. Alguns estados passaram a adotar estratégias para atrair investimentos e, por isso, o desenvolvimento de uma região ou estado muitas vezes é a causa do não desenvolvimento de outro. Lopreato (2002) destaca que os estados passaram a atuar mais nas políticas de desenvolvimento por meio de negócios articulados regionalmente e, para isso, utilizam mecanismos como a captação de recursos por intermédio de bancos estaduais ou regionais, ou oferecendo incentivos fiscais.

O Estado brasileiro, por seu perfil de atuação em muitos setores por meio das empresas estatais, buscou fazer investimentos para a economia brasileira na década de 1970, principalmente por intermédio do II Plano Nacional de Desenvolvimento-II PND. Diniz (1995) relata que muitos dos investimentos foram realizados fora do Estado de São Paulo, ou seja, esses investimentos levaram muitas indústrias para outras regiões com menor dinâmica econômica. $\mathrm{O}$ avanço da fronteira agrícola e a extração mineral também são destacados pelo autor como fatores que mudam essa dinâmica regional. Mas, as disparidades continuam a ocorrer, muitas vezes, em nível mais micro. Dessa forma, em algumas regiões como o nordeste brasileiro, mesmo possuindo uma indústria moderna de alguns complexos como o petroquímico e a agricultura 
irrigada para exportação, persiste a pobreza e a agricultura de subsistência em muitos locais.

Com a crise da dívida na década de 1980, associado à alta taxa de inflação, o planejamento, principalmente por parte do Estado, é deixado de lado. Belluzzo e Almeida (1992) retratam sobre essa crise financeira do Estado, ocasionada pela brusca interrupção da oferta voluntária de recursos externos e pelas políticas adotadas para sanear o desequilíbrio no balanço de pagamentos, de forma que esse perde cada vez mais os mecanismos de ação.

$\mathrm{Na}$ década de 1990, com a abertura econômica e a adoção de políticas neoliberais, foi muito difundida a ideologia de que o local poderia se desenvolver. Dessa forma, cada vez mais abandona políticas de desenvolvimento regional. Órgãos de cooperação internacional, como o Banco Mundial (The World Bank), entre outros, fomentavam mais a organização local, principalmente o denominado capital social, sendo que, muitas vezes, nem ao menos o Estado intermediava os recursos, devido à forte ideologia de que esse era corrupto.

Mas, com a implementação das medidas neoliberais, passam a surgir certas preocupações, como a redução da pobreza, pois as regiões estão cada vez mais expostas a uma competição internacional. Hespanhol (2010) descreve que as instituições multilaterais, como o Banco Mundial e o Banco Interamericano de Desenvolvimento-BID, a partir de experiências do Programa Ligações Entre Ações do Desenvolvimento da Economia Rural-LEADER, implantado na União Europeia a partir dos anos de 1990, passaram a condicionar a concessão de financiamentos aos países periféricos à incorporação, nos seus programas de desenvolvimento rural, de pressupostos e estratégias visando à redução da pobreza, bem como o estímulo às formas de organização coletiva, a conservação dos recursos naturais e a visão mais integrada dos espaços rurais e urbanos por meio da perspectiva territorial. Porém, uma crítica da autora é que as ações não consideravam as particularidades que caracterizam esses países.

Dessa forma, mesmo o desenvolvimento de ações em determinadas regiões, em espaços menores ou em determinados grupos de indivíduos, prevalecem muitos problemas econômicos como a baixa dinâmica e situações mais extremas como a pobreza. Para isso, muitas políticas públicas passam a serem elaboradas e executadas em espaços 
menores, por exemplo, nos territórios. Em áreas rurais, também se busca uma maior articulação do espaço entre atividades rurais e urbanas, de forma a fornecer aos indivíduos os seus direitos constitucionais, como acesso a determinados serviços - esgoto, etc.que, por muito tempo, ficaram mais restritos às áreas urbanas e de grandes metrópoles. Ou seja, deixa-se de pensar em ações setoriais e para ações mais do meio como um todo.

\section{TERRITÓRIO COMO ESPAÇO DE ARTICULAÇÃO'}

Durante muito tempo, as políticas públicas tiveram um enfoque mais urbano na oferta de infraestrutura, sendo que, muitas vezes, os investimentos concentraram-se em grandes centros urbanos. Quanto ao meio rural, a ênfase sempre foi mais setorial, ou seja, em ações específicas como o crédito rural, dando uma maior ênfase na produção do que nas condições de vida dos trabalhadores e moradores das zonas rurais e das pequenas cidades.

Desde a constituição brasileira de 1988, busca-se, na atuação das políticas públicas, uma descentralização das ações (NOGUEIRA, 1997). Para isso, o Estado brasileiro começou a constituir grupos de estudos para conhecer mais a fundo os problemas, suas causas, consequências e possíveis soluções para reduzir as desigualdades regionais. Porém, em alguns períodos, acreditava-se que bastava a formação de "capital social" e o desenvolvimento local ocorreria. Mas, com a verificação por meio de diagnósticos que muitos problemas não foram resolvidos, coube aos formuladores de políticas públicas (policy makers) repensarem como e onde deveriam agir para reverter o problema. Assim, começa a ser pensada a PNDR.

Observa-se, no entanto, que o problema do Desenvolvimento Territorial Rural não é a ausência de capital social no nível micro, mas, sim, a dificuldade de encontrar uma forma de transformar esses laços comunitários em elementos positivos para a geração de bem-estar. Como um território não é um ente isolado, ou uma autarquia, não basta identificar as formas de governança e os grupos de interesse locais.

\footnotetext{
1 Essa seção conta com alguns trechos atualizados que foram extraídos de Belik (2010).
} 
Também é preciso verificar como esses elementos se conectam com o Estado e com os agentes da sociedade civil (MULS, 2008; GRAZIANO DA SILVA, 2000).

As políticas de desenvolvimento que se iniciam no Plano Plurianual-PPA, 2003/2006, por intemédio da proposta do governo Lula (Brasil de Todos) deveriam ter um componente regional com base no princípio de que o mercado não pode ser o único determinante do ordenamento territorial, porque promove concentração econômica e, dessa forma, acirra as desigualdades sociais. Dessa forma, incorpora-se à necessidade de reduzir as desigualdades econômicas entre as regiões, considerando as diversidades regionais, articulando com uma convergência das prioridades de gasto da União, estados e municípios, fortalecendo os arranjos produtivos locais, promovendo uma, profunda reformulação dos instrumentos de atuação regional e desconcentrando as bases científicas e tecnológicas, entre outras medidas. Dessa forma, em consonância com a orientação do PPA 2003/2006, o governo federal formulou a PNDR que reconheceu a desigualdade existente em todo território nacional, utilizando a escala microrregional (SENRA, 2010).

Porém, mesmo uma política regional dificilmente consegue abranger todas as regiões e grupos sociais. Assim, também se cria políticas para o desenvolvimento de regiões com baixa dinâmica econômica onde prevalece o rural. Nessas regiões, as ações deixam de ser por setor, como por exemplo, as tradicionais políticas agrícolas direcionadas a determinada atividade, e começam a atuar no meio como um todo, com as preocupações de sustentabilidade da produção, de melhoria das condições de vida dos residentes e trabalhadores do meio rural, entre outros. Schneider (2004) descreve quatro elementos que estão em pauta no desenvolvimento rural: diminuição da pobreza rural, o protagonismo dos atores sociais e sua participação política, a territorialidade e a sustentabilidade ambiental. Ou seja, o desenvolvimento rural articula-se com o desenvolvimento territorial e vice-versa.

Entre os projetos de desenvolvimento territorial mais voltados para o meio rural, o Ministério do Desenvolvimento Agrário-MDA, por meio de seus Planos Territoriais de Desenvolvimento Rural SustentávelPTDRS, destaca que essa nova visão de planejamento do desenvolvimento rural deriva da necessidade de articulação das políticas 
públicas, da formação de parcerias, potencializando resultados. As ações buscam o fortalecimento da gestão social e das redes sociais de cooperação, assim como a dinamização econômica dos territórios (MDA, 2005).

Assim, os territórios são utilizados como um mecanismo de coordenação. Benko (1996), referindo-se à economia das convenções, descreve que um território deve ser formado por um conjunto de atores e objetivos reais, ou tratados ou convencionados para resolver um problema de coordenação. Assim, a dinâmica dos laços sociais são importantes para serem estudados. Benko (2001) cita que a consideração dos fatores locais nas dinâmicas econômicas aparece, hoje, como uma evidência e uma necessidade, abrindo via rumo à diversificação das políticas econômicas, sociais e culturais.

$O$ enfoque territorial no desenvolvimento rural pode ser definido como um processo que busca mudar as estruturas produtivas e institucionais de um espaço rural com a finalidade de reduzir a pobreza. A transformação produtiva pretende articular a economia de território a mercados dinâmicos e a transformação institucional busca facilitar a interação dos atores sociais (dentro e fora do território), oferecendo maiores oportunidades à população pobre, para que se integrem ao processo de desenvolvimento e participem de seus benefícios (FERNÁNDEZ; RODRÍGUEZ \& SEPÚLVEDA, 2004).

Costuma-se apontar a existência de um território a partir da identidade comum compartilhada entre os seus habitantes e as instituições que são construídas em torno dessa identidade. Por esse motivo, os territórios não se configuram como áreas geográficas delimitadas, mas como construções sociais erigidas a partir de um capital social acumulado ao longo de muitos anos (PUTNAM, 2007). Mesmo que os atores não estejam estabelecidos em um determinado território do ponto de vista físico, eles compartilham laços sociais e culturais que possuem em comum.

A descrição dessas características do desenvolvimento territorial indica que estejamos eliminando o aspecto geográfico da definição de território. Pelo contrário, a geografia e os seus determinantes ainda têm um peso expressivo na capacidade de desenvolvimento de uma localidade. Ironizando a apologia da globalização, Jimenez (2001) lembra que chegou a se anunciar, juntamente com o "fim da história", o 
"fim da geografia" para demonstrar que a globalização estava tornando irrelevantes as distâncias. Entretanto, do ponto de vista do crescimento econômico e dos seus aspectos dinâmicos, observa-se que regiões isoladas, ou seja, não vinculadas às linhas de transporte e comunicação, tendem a recriar aspectos autárquicos (BERDEGUÉ e SCHEJTMAN, 2007). O lado negativo dessas tendências é o aumento da brecha econômica entre essas localidades e outras mais produtivas, que atraem a mão de obra mais qualificada e apresentam uma maior rentabilidade marginal ao capital investido. Como resultado, permanecem, nas regiões isoladas, os mais pobres (aqueles não tiveram a oportunidade de emigrar) e as atividades econômicas mais precárias, elementos que aprofundam o isolamento dessas localidades.

As recentes políticas públicas de desenvolvimento rural vêm utilizando o enfoque territorial em sua implementação, Ortega et al. $(2009$, p.7) elabora alguns pressupostos para esse enfoque territorial:

- grandes déficits de pobreza se concentram nos ambientes rurais (campo e municípios de perfil rural);

- o rural é tomado como um espaço e se diferencia da abordagem que o identifica com o setor agropecuário;

- o processo de desenvolvimento deve se dar com a inserção em mercados dinâmicos (regionais, nacionais e internacionais);

- a introdução de inovações tecnológicas produtivas e organizacionais, reforma institucional, com a criação de novos modelos de governança local, deve levar a cabo a descentralização administrativa e/ou política;

- o caráter intermunicipal dos arranjos socioprodutivos, na busca de sinergias locais com vistas à elaboração de um projeto intermunicipal de desenvolvimento, permite explorar as vantagens comparativas e competitivas de cada município.

- essa nova governança se sustentaria em função de uma concertação social, cujo resultado é um pacto territorial (inter e intra-classes e público-privado), com vistas ao desenvolvimento endógeno.

Com a preocupação de política de desenvolvimento territorial nas regiões predominantemente rurais, na elaboração do PPA 2008/2011, no ano de 2007, surge a proposta de criação dos Territórios da Cidadania (MDA, 2007). Os Territórios da Cidadania surgem como uma espécie de contraponto de equilíbrio ao Programa de Aceleração do 
Crescimento-PAC, como uma tentativa de dar unidade a um conjunto de ações antes dispersas por vários ministérios. Nele, são congregadas as ações de 19 estruturas ministeriais, sob coordenação da Casa Civil (FAVARETO, 2009). Assim, mesmo já possuindo programas de desenvolvimento territorial rural como os Territórios Rurais que tinham sido constituídos antes, o enfoque desses programas anteriores era mais rural, por exemplo, preocupações com a sustentabilidade da produção, entre outras.

Segundo Delgado e Pereira Leite (2011), enquanto os Territórios Rurais apresentavam um esquema centrado na Secretaria de Desenvolvimento Territorial-SDT do MDA, vinculando os diferentes colegiados territoriais ao Ministério, o processo de gestão do Programa Territórios da Cidadania estabelece um tripé: Comitê Gestor Nacional, Comitês de Articulação Estadual e os Colegiados Estaduais. Do Comitê Gestor Nacional fazem parte os representantes dos ministérios. Os comitês de articulação estadual buscam articular órgãos federais, estaduais e representações das prefeituras dos municípios envolvidos nos territórios. Os colegiados territoriais são compostos por representantes das três esferas de governo e da sociedade em cada território.

Ortega e Mendonça (2007) descrevem que políticas públicas, por exemplo, de combate à pobreza e às desigualdades sociais e regionais podem ter um enfoque territorial mas seguir um caminho liberalizante, ou seja, fomentar o desenvolvimento autônomo. Porém, essas políticas que foram difundidas por muitos órgãos de cooperação internacional e governos não tiveram tanto êxito. Houve, assim, a necessidade de repensar essas políticas. Para isso, vê-se que o Estado não deve ser eliminado das ações, pois tem um papel importante na articulação com as condições locais de organização. Os autores enfatizam que no Governo do Presidente Fernando Henrique Cardoso se deu mais ênfase às ações locais. No Governo Lula, a evolução dessa política territorial foi articular as ações públicas de caráter nacional e combinando com outras políticas sociais como as de transferência de renda. Dentre as políticas de incentivo do Governo Lula foi o fomento de Consórcios de Segurança Alimentar e Desenvolvimento Local (CONSAD), entre outras.

O Programa Territórios da Cidadania tem uma perspectiva de articulação das políticas territoriais como o fomento à organização, 
porém, de forma a interagir com o Estado em ações que vão além do rural, busca a melhoria da qualidade de vida das pessoas e garantia dos direitos à cidadania. Assim, é uma política de forte articulação com o Governo Federal através da Secretaria de Desenvolvimento Territorial (SDT) do Ministério do Desenvolvimento Agrário (MDA). Essa política busca reduzir as desigualdades regionais, mas também articulada com diversos ministérios, seja fomentando ações locais como os incentivos às atividades geradoras de emprego e renda, bem como facilitar a oferta de serviços públicos e benefícios socais aos diversos indivíduos excluídos de muitas ações públicas.

O território passa a ser um espaço de coordenação das atividades e de reivindicações das demandas sociais em busca de uma melhor aplicação dos recursos públicos, integrando ações de política agrícola em si com ações de educação, saúde, infraestrutura, cultura, etc. Uma grande importância dessa política pública é perceber que o meio rural não é apenas a agropecuária, pois o cidadão que lá reside deseja ter acesso a muitos serviços, como saúde, educação, telefonia, internet etc. Muitas outras políticas davam pouca importância às pessoas do meio rural. Assim, o Programa espera em médio e longo prazo que a sistemática de planejamento da oferta de políticas públicas para o meio rural brasileiro com foco na abordagem territorial se consolide e integre os três níveis federativos e a sociedade local organizada. Echeverri (2010, p.100) descreve que "no fundo, existe um princípio de reivindicação, baseado na vontade de romper um longo histórico de exclusão política".

Dentre a lógica do território como espaço de organização social, segundo Costa e Brito (2010), cada vez mais as políticas públicas necessitam ser pensadas de forma regionalizada e, em grande, parte isto caminha em paralelo com um processo de descentralização das ações de governo. Ou seja, planejamento, regionalização, descentralização e participação popular caminham de forma conjunta para valorizar as especificidades de determinados espaços, bem como as individualidades e sentimentos de pertencimento das comunidades locais. Assim, o conceito de região é cada vez mais substituído pelo de território, entendido como um espaço construído social e historicamente por meio da cultura, das instituições micro e mesorregionais e da política. O território, seja este uma cidade ou uma região é, dessa 
forma, um emaranhado de interesses de uma comunidade - um espaço de disputa por poder -, possuindo uma identidade própria que, em grande parte, requer autonomia para sua delimitação.

Ou seja, a definição de territórios em torno de características puramente geográficas, como o seu desenho em torno de bacias hidrográficas, por exemplo, não garante por si só a coesão necessária para que esse território possa traçar uma estratégia comum de desenvolvimento. No entanto, o reconhecimento de um território e a identificação de suas características pode ser um ponto de partida para a sua transformação.

A maior parte dos territórios de países pobres são claramente deprimidos e, portanto, as suas perspectivas de emancipação e desenvolvimento já partem de um patamar muito mais baixo. Muitas vezes, mesmo com a economia nacional empreendendo uma trajetória de crescimento, o incremento geral nos indicadores econômicos pode não levar ao crescimento de certas regiões que se encontram deprimidas, dado o grau de marginação desses territórios e o seu alheamento em relação aos movimentos mais gerais da economia. No entanto, regiões pobres não representam necessariamente regiões despojadas de institucionalidade e de organização da população. Em função da falta de alternativas econômicas, o tecido social desses territórios sofre um esgarçamento constante com a emigração, os conflitos agrários e a devastação do meio ambiente. No entanto, havendo uma prévia organização dos atores sociais, essa falta pode funcionar como uma alavanca para a decolagem de tais economias.

O desenvolvimento das atividades agrícolas pode colaborar para a diminuição da pobreza, muito embora o crescimento de atividades não agrícolas, em termos macroeconômicos, tenha um efeito ainda maior sobre ela (BRESCIANI e VALDÉS, 2007: 6). Mesmo considerando a agricultura como única opção de crescimento, é preciso definir exatamente a qual agricultura estamos nos referindo. Afinal, "o crescimento baseado em produções de alto valor agregado com ligações robustas com a agroindústria pode reforçar a conexão entre crescimento agrícola e mercado de trabalho" (BRESCIANI e VALDÉS, 2007:7).

$\mathrm{Na}$ implementação das políticas públicas no espaço territorial, há a presença de vários atores sociais e níveis hierárquicos da gestão 
pública, o que pode gerar conflitos por interesses de determinados atores ou grupos sociais. Além do espaço do território, algumas ações podem extrapolar esse espaço. Dentre os objetivos de organização e atuação das políticas públicas no enfoque territorial o MDA (2003, p. 26) destaca:

o enfoque territorial é uma visão essencialmente integradora de espaços, atores sociais, agentes, mercados e políticas públicas de intervenção. Busca a integração interna dos territórios rurais e destes com o restante da economia nacional, sua revitalização e reestruturação progressiva, assim como a adoção de novas funções e demandas.

Nos Territórios da Cidadania, os colegiados territoriais têm uma função de ser o elo entre as esferas de governo atores sociais do território. Delgado e Pereira Leite (2011, p.436) relatam as atribuições dos colegiados territoriais:

i) divulgar as ações do programa; ii) identificar demandas locais para o órgão gestor priorizar o atendimento (de acordo com critérios, sistemas de gestão pré-estabelecidos, especificidades legais e instâncias de participação existentes)b; iii) promover a interação entre gestores públicos e conselhos setoriais; iv) contribuir com sugestões para qualificação e integração de ações; v) sistematizar as contribuições para o Plano Territorial de Ações Integradas; vi) exercer o controle social do programa.

Ou seja, além de identificar as demandas, o colegiado territorial tem a função de exercer o controle social e contribuir para a gestão do território. A figura 1 apresenta a gestão dos Territórios da Cidadania. A visualização das demandas, a gestão do território e o atendimento das reivindicações dependerão de uma articulação Nacional-Territorial, em conjunto com uma articulação estadual, sendo que tanto a organização dos atores sociais do território quanto a relação com outros elos, por exemplo, como os serviços estaduais, poderá facilitar ou dificultar que determinadas políticas públicas sejam implementadas. 
Figura 1. Gestão do Programa Territórios da Cidadania

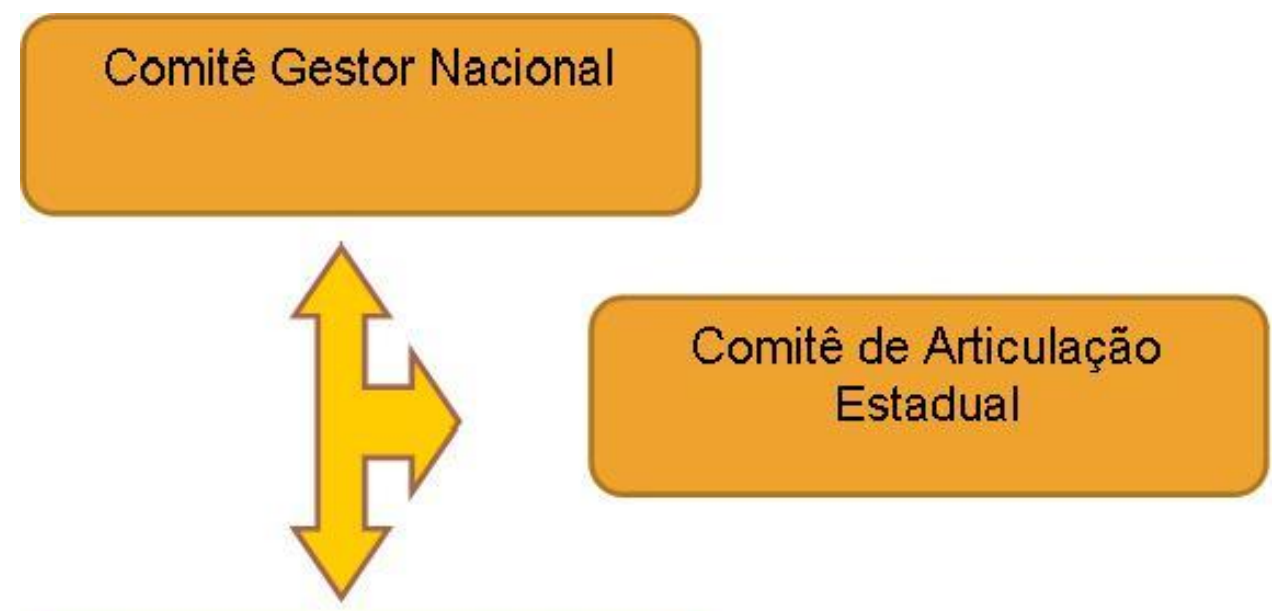

\section{Colegiado Territorial}

Fonte: Territórios da Cidadania (2009).

O Programa Territórios da Cidadania abrange 33\% dos municípios brasileiros, especialmente os localizados em regiões mais rurais como se vê no Quadro 1. No grupo de ações do governo federal, a destinação de recursos para 2009 foi de 23,5 bilhões de reais em Apoio a Atividades Produtivas, Cidadania e Acesso a Direitos e Qualificação da Infraestrutura (TERRITÓRIOS DA CIDADANIA, 2009). Porém, como bem destacado por Lopes e Kerbauy (2009), muitos investimentos no Programa já estavam no orçamento, como aqueles oriundos do Programa Bolsa Família - PBF e os Benefícios de Prestação Continuada BPC, dentre outros que não se configuram como recursos novos. Ou seja, o enfoque territorial busca a articulação de várias políticas públicas, mas não necessariamente está aplicando novos recursos.

Quadro 1: Abrangência do Programa Territórios da Cidadania

\begin{tabular}{|l|l|}
\hline Municípios beneficiados & 1.852 (33\% dos municípios brasileiros) \\
\hline População & 42,4 milhões (23\%) \\
\hline População rural & 13,1 milhões $(46 \%)$ \\
\hline Agricultores familiares & 1,9 milhão $(46 \%)$ \\
\hline
\end{tabular}




\begin{tabular}{|l|l|}
\hline Assentados da reforma agrária & 525,1 mil famílias (67\%) \\
\hline Pescadores & $210,5 \mathrm{mil}(54 \%)$ \\
\hline Comunidades Quilombolas & $810(66 \%)$ \\
\hline Terras Indígenas & $317(52 \%)$ \\
\hline
\end{tabular}

Fonte: Territórios da Cidadania (2009).

Além das ações como o fomento aos serviços básicos aos cidadãos, busca-se uma maior integração entre o rural e o urbano na promoção do desenvolvimento como na capacitação dos indivíduos para o mercado de trabalho, entre outros. Segundo Graziano da Silva (1996), os programas de combate à pobreza rural não podem ter mais como referência apenas reinserir populações marginalizadas da modernização excludente em atividades apenas no âmbito do próprio mundo rural, ignorando o forte processo de urbanização a que ele está submetido. A população do meio rural diminuiu muito, principalmente pelos jovens que buscaram as cidades para melhores condições de vida e para fugir dos baixos salários das atividades agrícolas. Assim, mesmo com um maior crescimento da economia com uma maior geração de empregos, o campo pode-se beneficiar com a oferta de novos serviços, como o lazer, turismo, preservação do meio ambiente etc., bem como bens não agrícolas, como moradia, transporte, artesanato etc.

Dessa forma, o Programa Territórios da Cidadania se apresenta como o fortalecimento dos territórios de identidade do Programa Desenvolvimento Sustentável de Territórios Rurais - PDSTR que tinha um enfoque mais no rural. Segundo Bonnal (2008), a ruptura estaria representada por diversas inflexões importantes. Em primeiro lugar, destaca-se o realismo com que foi encarada a nova estratégia de combate à pobreza rural. Assim, muito se falou sobre a pouca eficiência do PDSTR com respeito a esse objetivo, seja pela sua diluição no contexto de um objetivo mais geral de desenvolvimento de territórios de identidade, seja pelos parcos recursos financeiros e humanos disponibilizados. Com esse novo programa, o combate à pobreza rural converteu-se no principal objetivo de ação, dando lugar a uma série de opções metodológicas precisas, começando pelo critério de seleção (situações com menor $\mathrm{IDH}^{2}$ ). $\mathrm{O}$ incremento significativo de verba e

\footnotetext{
2 IDH - Índice de Desenvolvimento Humano
} 
pessoal também contribuiu para essa mudança de postura. Não se trata somente de redistribuir os recursos precedentes, mas de ampliar e concentrar o financiamento para situações geográficas e humanas de maior necessidade, como também de multiplicar e combinar as políticas sociais e as competências técnicas de diferentes ministérios. Uma segunda ruptura com o PDSTR é a mudança do paradigma implícito que sustenta cada programa. O anterior se fundamentava na ideia de território de identidade, que supõe a existência de um corpo de normas (simbólicas ou não) específicas da sociedade local. Dessa forma, o programa objetivava ajudar a coletividade local na definição e implementação de ações coerentes com as normas aí estabelecidas, respondendo a objetivos compartilhados.

Buarque (2012) descreve que, enquanto o programa Territórios Rurais de Identidade organiza as demandas nos planos do território, o programa Territórios da Cidadania exerceu um papel de articulação da oferta de projetos federais que poderiam ser implementados nos diferentes territórios. Essa oferta é levada para o território de modo a ser analisada e priorizada pela sociedade local organizada. Assim, os Territórios da Cidadania são delimitados em regiões onde se verifica a problemática da baixa dinâmica econômica e o Estado busca intervir por meio de políticas sociais e de inserção produtiva.

Os Territórios da Cidadania estão localizados em regiões com determinadas características como:

- Territórios com menor IDH;

- Territórios com maior concentração de beneficiários do PBF;

- Concentração de agricultura familiar e assentamentos da reforma agrária;

- Maior concentração de populações quilombolas e indígenas;

- Territórios com maior número de municípios com baixo dinamismo econômico (Tipologia das Desigualdades Regionais da PNDR);

- Territórios com maior organização social (capital social).

A figura 2 mostra a distribuição dos Territórios da Cidadania no Brasil. Mesmo em estados da federação mais desenvolvidos, há presença de áreas que estão inseridas nos critérios de elegibilidade da política. Respeita o critério de áreas contínuas por estados, pois diferencia-se de 
algumas organizações que atuam mais em nível estadual. Dessa forma, algumas áreas, mesmo possuindo características econômicas e ambientais semelhantes, podem ser territórios diferentes devido aos limites estaduais. Ou seja, acima de tudo, o território é um espaço de organização social e de articulação da atuação das políticas públicas de diferentes esferas administrativas e interações com os atores sociais. 
Figura 2. Mapa de localização dos Territórios da Cidadania

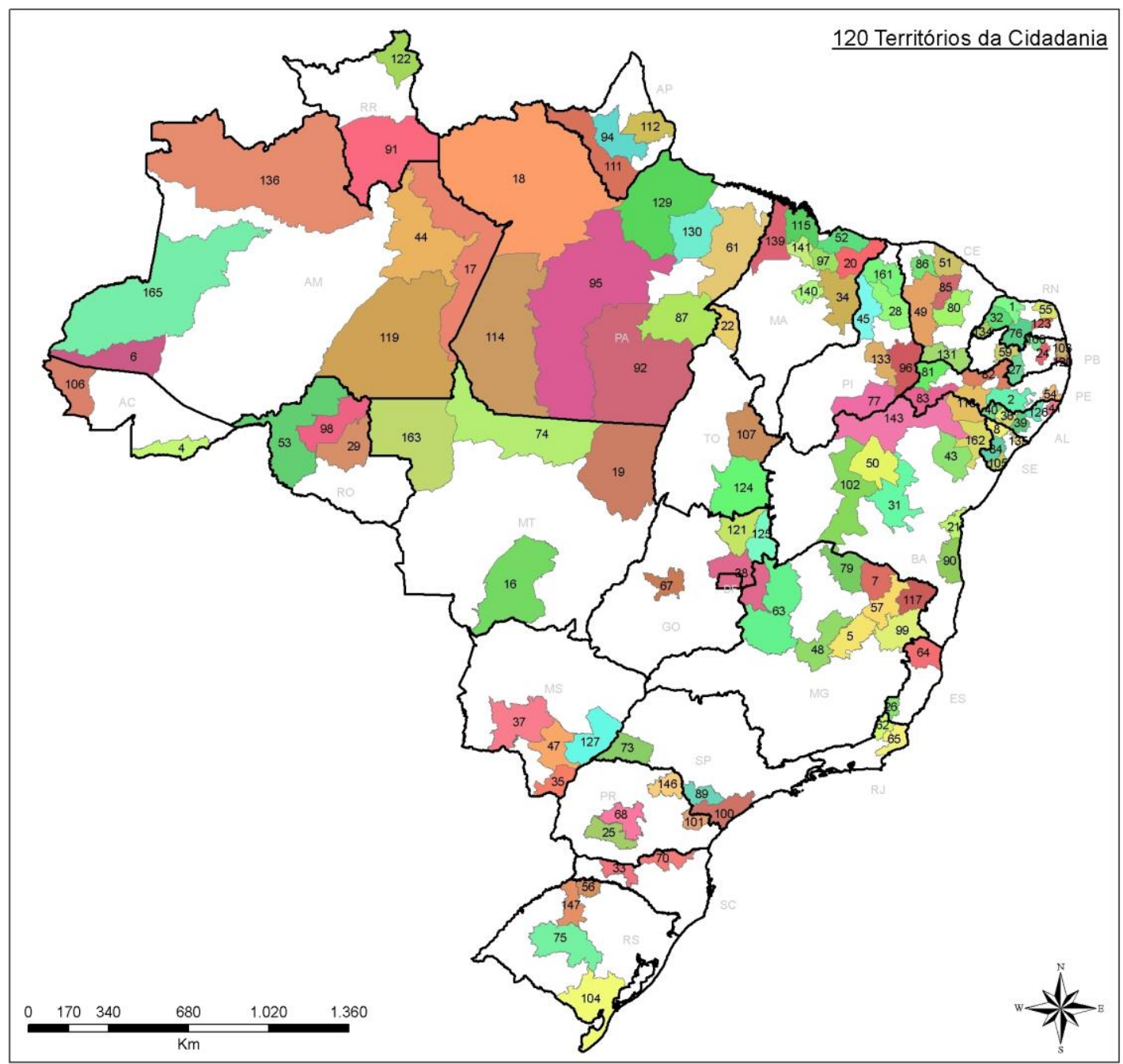

Fonte: Sistema de Informação Territoriais - SIT (2015)

A distribuição geográfica das regiões de predominância rural com baixa dinâmica econômica, ou seja, a distribuição dos Territórios da Cidadania no Brasil mostra que as desigualdades não são apenas entre regiões, mas, mesmo em estados com alta dinâmica econômica, por exemplo, São Paulo, persistem as desigualdades. Isso demonstra a importância de políticas que vão além da região, para corrigir disparidades que ocorrem em escalas menores.

No programa Territórios da Cidadania, além do aporte de recursos do governo federal, os estados também contribuem com a oferta de recursos, ou seja, além da organização, os estados também podem complementar para o esforço de diminuir as desigualdades. Em algumas 
regiões há além dos Territórios da Cidadania os Territórios Rurais, que buscam apoiar a organização e o fortalecimento institucional dos atores sociais locais na gestão participativa, porém, com ações mais voltadas para o rural.

Mesmo o Programa Territórios da Cidadania tendo como premissa uma abordagem conjunta de políticas públicas mais integradas, fugindo do enfoque setorial (rural), persistem alguns problemas. Araujo (2010) verificou, por meio de consultas aos documentos, que, em muitas políticas territoriais é a Secretaria de Agricultura ou de Desenvolvimento Agrário que comanda o processo, o que dificulta a integração de outras políticas, dado sua natureza setorial. Araujo (2010, p. 210) destaca que:

um dos estados de maior avanço é a Bahia, onde existe um Conselho Estadual de Desenvolvimento Territorial (Cedeter) atuante, presidido pelo Secretario de Planejamento, e onde a opção pela territorialização das políticas estaduais parece bem firme. O exemplo baiano deixa a lição de que é preciso investir neste elo entre as políticas nacionais e locais.

Assim, as políticas públicas que, na década de 1950, tinham um enfoque mais regional passam a ser trabalhadas de forma mais segmentada, seja setorial ou territorial. A atuação de uma política pública no nível territorial busca inserir além do setorial, por exemplo, nos incentivos à desigualdade no meio rural esse espaço está cada vez mais associado ao urbano, necessitando de uma articulação conjunta entre os dois ambientes. Essa é uma proposta do Programa Territórios da Cidadania, porém, com alguns problemas em alcançar esse objetivo.

Verifica-se que as políticas de desenvolvimento territorial devem integrar cada vez mais atores que vão além do rural, bem como ter uma maior articulação entre as diferentes esferas governamentais. Araujo (2010) também descreve que os gestores dos ministérios não estão acostumados a negociar as ações que coordenam em processos amplamente participativos e os agentes locais não têm informações suficientes, e alguns não têm um lastro de conhecimento que possibilite intervenções qualificadas no processo de gestão das políticas territoriais. Ou seja, a política territorial tem que ser trabalhada em várias instâncias e com constantes aperfeiçoamentos e discussões para 
que simplesmente as decisões não se concentrem em um pequeno número de indivíduos mais capacitados.

\section{CONSIDERAÇÕES FINAIS}

As políticas de desenvolvimento regional impulsionadas pelo GTDN, que tiveram uma grande contribuição de Celso Furtado, marcam o início de políticas de desenvolvimento regional no Brasil com o objetivo de diminuir as desigualdades regionais. Mesmo com as mudanças no decorrer de sua implementação com o regime militar, algumas ações foram implementadas, impulsionado o desenvolvimento de muitas atividades na região Nordeste, mesmo que não tenha resolvido todos os problemas daquela região.

Com a perda de capacidade do Estado pelas dívidas da década de 1980 e das medidas neoliberais da década de 1990, diminuiu-se o planejamento e a execução das ações por parte do Estado, deixando que a inserção de determinadas regiões ocorresse pela inserção competitiva nos mercados. Mas, com o decorrer do tempo e verificação que muitas desigualdades continuaram, o Estado volta a atuar por meio da PNDR. Além disso, criou-se ações específicas para regiões com predominância de determinados grupos sociais, no caso, para as regiões de predominância rural e com baixas dinâmicas econômicas, criou-se o Programa Territórios da Cidadania.

Políticas territoriais como o Programa Territórios da Cidadania passam a ser pensadas com o objetivo primordial de reduzir a pobreza, nesse caso, a pobreza de regiões rurais. Para isso, busca-se articular ações como a inserção produtiva tanto em atividades rurais quanto urbanas. Mas, busca-se principalmente oferecer benefícios aos cidadãos, tanto os constitucionais como acesso à saúde, à educação, à aposentadoria rural etc., bem como os serviços básicos de infraestrutura, como água tratada, esgoto, telefonia etc. O território é o espaço de integração de várias políticas públicas, ou seja, de coordenação das várias políticas. Não necessariamente inclui-se novos recursos para essas regiões, mas procura-se integrar as várias atividades em torno de um programa. O programa brasileiro é bastante recente e não foram feitas avaliações diretas de seus resultados. No 
entanto, a característica dos Territórios da Cidadania, assim como de outros programas similares na América Latina é o fato de estarem cobrindo um público que já se beneficia por outros programas como o Bolsa Família, por exemplo e, por isso, poderia partir-se de um patamar mínimo mais adequado para empreender suas atividades.

As políticas territoriais especialmente no que se refere às ações para o rural têm uma grande importância por romperem com políticas de cunho puramente setorial. Nesse ambiente busca-se uma maior interação entre os atores sociais, onde princípios como a participação cada vez mais fazem parte do discurso, porém, há a necessidade de uma articulação do local com o nacional para um projeto de desenvolvimento com o objetivo de diminuir as desigualdades regionais, bem como entre grupos sociais. O local tem que ser um ponto de ação que requer suas demandas, mas não pode ser encarado como se todas as soluções viessem apenas da organização do local.

\section{REFERÊNCIAS}

ARAUJO, T. B. Pensando o futuro das Políticas de Desenvolvimento Territorial no Brasil. In: ARAUJO, T. B. (Coord.). Políticas de desenvolvimento territorial rural no Brasil: avanços e desafios. Série Desenvolvimento Rural Sustentável; v.12. Brasília: IICA, 2010, p. 197217.

ARAUJO, T. B.; SANTOS, V. M. dos. Desigualdades regionais e Nordeste em Formação Econômica do Brasil. In: Tarcisio Patricio de Araújo, Salvador Teixeira Werneck Vianna e Júnior Macambira (orgs.). 50 anos de Formação Econômica do Brasil: ensaios sobre a obra clássica de Celso Furtado. Rio de Janeiro: IPEA, 2009.

BELIK, W. Desenvolvimento Territorial e Soberania Alimentar In: ALMEIDA FILHO, N. \& RAMOS, P. Segurança Alimentar, Produção Agrícola e Desenvolvimento Territorial. Campinas: Alínea P. 169-192, 2010.

BELLUZZO, L.G. e ALMEIDA, J.S. A crise da dívida e suas repercussões sobre a economia brasileira. In: Belluzzo e Batista Jr. (orgs). A luta pela sobrevivência da moeda nacional. Rio de Janeiro, Paz e Terra, 1992. 
BENKO, G. Géographie Économique et Théorie de la Régulation. Finisterra, v. XXXI, n. 62, p. 7-28, 1996.

A recomposição dos espaços. Interações - Revista Internacional de Desenvolvimento Local, v. 1, n. 2,p. 7-12, mar. 2001.

BeRdeGuÉ, J. A.;SCHEjTMAN, A. La Desigualdad y la Pobreza Como Desafíos para el desarrollo Territorial Rural. Seminario de Expertos sobre el Crecimiento Agrícola y la Persistencia de la Pobreza Rural, Santiago do Chile: FAO, 2007.

BONNAL, P. Território da cidadania, evolução ou revolução das políticas públicas no meio rural. Observatório de Políticas Públicas para Agricultura, Programa de Pós- Graduação de Ciências Sociais em Desenvolvimento, Agricultura e Sociedade, UFRRJ, n. 14, fev. 2008.

BRESCIANI, F.; VALDÉS, A. The Role of Agriculture in Poverty Reduction: a Syntesis of the Country Case Studies In: BRESCIANI, F.; VALDÉS, A. (editores). Beyond Food Production - The Role of Agricultures in Poverty Reduction. Cheltenham: Edward Elgar, 2007.

BUARQUE, Sérgio C. Políticas públicas de desenvolvimento territorial no Brasil: análise e sugestões de aprimoramento. In: MIRANDA, C.; TIBURCIO, B. (Orgs.). Reflexões e Proposições de Políticas Públicas de Desenvolvimento Territorial. Brasília: IICA, 2012. Série Desenvolvimento Rural Sustentável; v.15. p. 127-186.

CANO, W. Raízes da Concentração Industrial em São Paulo. São Paulo: HUCITEC, 3ªd., 1991.

--_-_. Desequilíbrios regionais e concentração industrial no Brasil 1930-1970. São Paulo: UNESP, $3^{a}$ ed., 1997.

COSTA, Eduardo José Monteiro da; BRITO, L. S. B. O Planejamento Territorial Participativo: A Experiência do Estado do Pará, Brasil. Scripta 
Nova: Revista Electrónica de Geografía y Ciencias Sociales, v. XIV, n. 331 (37), ago. 2010.

DELGADO, N. G.; PEREIRA LEITE, Sergio. Políticas de Desenvolvimento Territorial no Meio Rural Brasileiro: Novas Institucionalidades e Protagonismo dos Atores. DADOS - Revista de Ciências Sociais, v. 54, n. 2, p. 431-473, 2011.

DINIZ, C. C. A Dinâmica Regional Recente da Economia Brasileira e suas Perspectivas. Texto para Discussão IPEA Nº. 375. Brasília: IPEA, 1995.

ECHEVERRI, Rafael. Emergência e evolução do programa de Desenvolvimento Sustentável dos Territórios Rurais e nos Territórios da Cidadania. In: ARAUJO, T. B. (Coord.). Políticas de desenvolvimento territorial rural no Brasil: avanços e desafios. Série Desenvolvimento Rural Sustentável. v.12 Brasília: IICA, 2010.

FAVARETO, A. Retrato das políticas de desenvolvimento territorial no Brasil. Documento de Trabajo n. 26. Programa Dinámicas Territoriales Rurales. RIMISP, Santiago, Chile, 2009.

FERNÁNDEZ, Karol; RODRÍGUEZ, Adrián; SEPÚLVEDA, Sergio. Desarrollo rural, pobreza y seguridad alimentaria. Cuadernos Técnicos de Desarrollo Rural/IICA n. 26. San José, C.R., IICA, 2004.

FURTADO, Celso. Estrutura agrária no subdesenvolvimento brasileiro. In: FURTADO, Celso. Análise do modelo brasileiro. Rio de Janeiro: Nacional, 1972.

Formação econômica do Brasil. 34. ed. São Paulo: Companhia das Letras, 2006.

GIL, A. C. Como elaborar projetos de pesquisa. 3. ed. São Paulo: Atlas, 1991.

GRAZIANO DA SILVA, J. F. A nova dinâmica da agricultura brasileira. Campinas: UNICAMP, 1996. 
. El Desarrollo Local en Contextos de Globalización: Una reflexión desde la experiencia brasileña. Revista Internacional de sociología, Tercera Época, n. 27, p. 171-187, Sep-Dic 2000.

GTDN. Uma Política de Desenvolvimento Econômico para o Nordeste. Recife, $2^{\text {a }}$ ed., 1959.

HESPANHOL, Rosangela Ap. de Medeiros. A adoção da perspectiva territorial nas políticas de desenvolvimento rural no brasil. CampoTerritório: revista de geografia agrária, v.5, n.10, p. 123-147, ago. 2010.

HIRSCHMANN, A. O. Desenvolvimento por efeitos em cadeia: uma abordagem generalizada. In: CARDOSO, F. H. et all. (Orgs.). Economia e Movimentos Sociais na América Latina. São Paulo: Brasiliense, 1985.

JIMÉNEZ, E. M. Evolución de los Paradigmas y Modelos Interpretativos del Desarrollo Territorial. Serie Gestión Publica 13. Santiago do Chile: ILPES - CEPAL, 2001.

LOPES, E. B. M.; KERBAUY, M. T. M. Desenvolvimento local e a construção de uma nova territorialidade: a implantação do Programa Territórios da Cidadania no Norte Pioneiro do Paraná. Cadernos Gestão Pública e Cidadania, v. 14, n. 55, p.79-104, jul./dez. 2009.

LOPREATO, Francisco L. C. O colapso das finanças estaduais e a crise da Federação. São Paulo: Editora Unesp; Campinas: IE/Unicamp, 2002.

MINAYO, M. C. O desafio do conhecimento: pesquisa qualitativa em saúde. Rio de Janeiro: Abrasco, 2007.

MINISTÉRIO DO DESENVOLVIMENTO AGRÁRIO (MDA). Referências para o desenvolvimento territorial sustentável. Textos para Discussão, 4. MDA/IICA. Brasília: Conselho Nacional de Desenvolvimento Rural Sustentável/Condraf, Núcleo de Estudos Agrários e Desenvolvimento Rural/NEAD, 2003. 
Plano Territorial de Desenvolvimento Rural Sustentável - Guia para o Planejamento - Documento de Apoio $N^{\circ}$ 02, Brasília, novembro de 2005. Disponível em: <http://portal.mda.gov.br/o/3261361>. Acesso em 21 março 2015.

Secretaria de Desenvolvimento Territorial (SDT). Territórios da cidadania: proposta do Ministério do Desenvolvimento Agrário para redução da desigualdade social no meio rural brasileiro. Brasília: MDA, 2007.

MULS, L. M. Desenvolvimento local, espaço e território: o conceito de capital social e a importância da formação de redes entre organismos e instituições locais. Economia, Brasília (DF), v. 9, n. 1, p.1-21, jan./abr. 2008.

MYRDAL, Gunnar. Teoria econômica e regióes subdesenvolvidas. Rio de Janeiro: Saga, 1969.

NOGUEIRA, M. A. A dimensão política da descentralização participativa. São Paulo em Perspectiva, v. 11, n. 3, p. 8-19, jun./set. 1997.

ORTEGA, A. C. et al. Desenvolvimento Territorial Rural e Consórcios Intermunicipais: políticas de indução de arranjos sócios produtivos em Minas Gerais. In: XIV Encontro Nacional de Economia Política, 2009, São Paulo. Anais... A crise financeira mundial e as alternativas de desenvolvimento da América Latina. São Paulo: SEP, 2009.

ORTEGA, A.C.; MENDONÇA, N. Estratégias de Desenvolvimento Territorial no Brasil: continuidades e rupturas. In: Desenvolvimento Territorial, Segurança Alimentar e Economia Solidária. Campinas: Alínea, 2007.

PUTNAM, R. D. E Pluribus Unum: Diversity and Community in the Twenty-first Century - The 2006 Johan Skytte Prize Lecture Scandinavian Political Studies, v. 30, n.2. p. 137-174, 2007. 
SENRA, K. V. Políticas e instituições para desenvolvimento econômico territorial. O caso do Brasil. CEPAL: Serie Desarrollo territorial $\mathrm{N}^{\circ}$. 8, Santiago do Chile, fevereiro de 2010.

SCHNEIDER, Sérgio. A abordagem territorial do desenvolvimento rural e suas articulações externas. Sociologias, n. 11, p. 70-125, jan./jun. 2004.

SISTEMA DE INFORMAÇÃO TERRITORIAIS (SIT). Mapas. Territórios da Cidadania. Disponível em:

http://sit.mda.gov.br/images/mapas/tc/br_055_tcs_120_maio_2009.jp

g. Acesso em 21 mar. 2015.

TERRITÓRIOS DA CIDADANIA. Integração de políticas públicas para reduzir desigualdades. 2009. Disponível em:

http://www.territoriosdacidadania.gov.br/dotlrn/clubs/territriosrurais/p ageflip/download_orig_file?pageflip_id=2221713. Acesso em 21 mar. 2015.

Submetido em 09/02/2012

Aprovado em 24/03/2015

Sobre os autores

Armando Fornazier

Doutor em Desenvolvimento Econômico pela Universidade Estadual de Campinas (UNICAMP). Pós-Doutorando no Programa de Pós-Graduação de Ciências Sociais em Desenvolvimento, Agricultura e Sociedade da Universidade Federal Rural do Rio de Janeiro (CPDA/UFRRJ).

Endereço: CPDA/UFRRJ.

Endereço: Avenida Presidente Vargas, 417, $8^{\circ}$ andar. Centro. 20071-003 - Rio de Janeiro - RJ - Brasil.

E-mail: armandouenf@yahoo.com.br

Walter Belik

Professor Titular do Instituto de Economia da UNICAMP. Pesquisador do Núcleo de Economia Agrícola e Ambiental (NEA/UNICAMP).

Endereço: IE-UNICAMP. Rua Pitágoras, 353. Cidade Universitária. 13083-85 Campinas - SP - Brasil.

E-mail: belik@eco.unicamp.br 
Redes (St. Cruz Sul, Online), v. 20, nº 2, p. 47 - 68, maio/ago. 201578 